\title{
A GIS MODEL FOR LANDFILL SITTING
}

\author{
V.K. DESPOTAKIS ${ }^{1^{*}}$ \\ A.P. ECONOMOPOULOS ${ }^{2}$
}

Received: 19/03/06

Accepted: 28/09/06

\author{
${ }^{1}$ GIS Consultant, 4 Mastracha Street \\ Heraklion 71202 Greece \\ ${ }^{2}$ Professor, Environmental Engineering Dept. \\ Technical University of Crete, Chania 731 00, Greece
}

*to whom all correspondence should be addressed: e-mail: vdesp@tee.gr

\section{ABSTRACT}

The use of Geographical Information Systems (GIS) for Landfill Sitting is studied. The necessary spatial information required to determine the candidate sites for any type of terrestrial area (Community/Prefecture/Region/Country) is examined. This spatial information is then used for site selection via successive spatial operations: Buffering, overlaying and attribute calculations. The method is tested for the whole region of the island of Crete, producing spatial numerical results, which can be used as points of reference for any future Landfill Sitting study for this area.

In our study, the main spatial information required for Landfill Sitting is determined in such a manner, so that the spatial development of the region is assured to be sustainable for the future generations. This means that we try to include as much as possible Environmental I Ecological / Economic factors characterizing the region under consideration. These factors take the form of spatial information, organized in spatial layers. The layers are then inserted into the GIS model for (a) Landfill site exclusion, and (b) Landfill site evaluation. All spatial layers correspond to subcategories of the main categories, defined as follows (GIS model setup): A. NATURE / ECOSYSTEM, B. HUMAN ACTIVITIES, C. WATER RESOURCES / HYDROLOGY, and D. ANTIQUITIES.

The exclusion "rules" are then defined by varying buffer distances surrounding each of the above layers separately (distance maps). The total areas to be excluded for each Category are defined by overlaying (union) the various distance maps in a sequential order, with the final "exclusion" map to be the union of all the above sub/distance maps. The remaining areas are then to be evaluated individually.

The GIS model results showed that, for the island of Crete, and a moderate buffer distances ("restrictions") scenario, a total of $47.73 \%$ of the whole area is excluded when we consider restrictions residing from Category A. NATURE/ECOSYSTEM, $61.40 \%$ is excluded due to the HUMAN ACTIVITIES (Category B), $16.03 \%$ is rejected due to WATER RESOURCES/HYDROLOGY protection considerations (Category C), and only 1,04\% of the total island area is excluded due to existence of ANTIQUITIES (Category D). If we are to combine the above Categories (A-D), a total of $82.65 \%$ of the total area is to be excluded, or a total of $17.35 \%$ of the island area only is suitable for Landfill Sitting. The GIS model results defines precisely which these areas are, so small-scale research, based on these results, is required for the final site ranking and selection.

KEYWORDS: Landfill sitting, sustainable development, carrying capacity, geographical information systems, land uses, spatial analysis, modeling, spatial data processing.

\section{INTRODUCTION}

The use of GIS [1] has been successfully applied in the past for site selection for which specific requirements have to be fulfilled (known as the "Location-Allocation" methodology). The "best" location for a Supermarket in an urban area, the foundation of a new railway 
station etc., are some examples of such problems. In our case, the optimal selection of a Landfill Site is sought, meeting certain requirements (life years, capacity, minimum nuisance, landscape preservation, minimum visibility etc). Certainly, the GIS model will serve as a tool for such a selection and the final decision will still be left to the human researchers. However, the higher overall quality of the GIS model, the higher role it will play for the final decisions, and the higher help it will offer.

Throughout the years, the above "Location-Allocation" demands have resulted in GIS embedded tools which, provided the necessary spatial information - "layers" - are available, can successfully perform a number of spatial functions, to arrive to the desired target. These operations include, amongst others:

- buffering at specified distances surrounding a layer

- overlaying multiple layers together (with clip, union, intersect and merge operations)

- querying the results for meta-data creation

- linking the spatial layers to user-specified models

However, for a successful GIS model elaboration, the following issues have to characterize the modelling process:

- Selection of the proper software / hardware to build the model

- Careful selection of the model initial parameters, their inter-dependencies and the specific spatial functions which will be modelled.

- Accurate initial data/layers in both their spatial (position) and attribute (accompanying fields) dimensions.

- Careful selection of the scale, density and extend of data, reference system, coordinate units, attribute units.

- Well-documented data sources: date of collection, organisation, methodology, areal extend etc.

- In case of missing data: Methodology for filling the "gaps", interpolation methods, accuracies etc.

In the present study, special care has been taken so that the whole methodology developed, meets the above requirements. This was achieved by setting up the GIS model as carefully as possible, defining all possible spatial information categories and subcategories which are required for Landfill Sitting, taking additionally into account:

(a) local spatial characteristics (for example small islands exclusion, NATURA areas etc)

(b) existing low restrictions (for example excluding areas with distances of less than $500 \mathrm{~m}$ from urban areas, considering archeological sites etc.)

Although the model was numerically tested for the island of Crete, the GIS model can be successfully used for other regions also, provided the necessary spatial information, specific conditions and local law restrictions knowledge is available.

In the following chapter, the detailed GIS model setup is given, together with all necessary spatial layers, functions, and constraints it contains.

\section{GIS MODEL DESCRIPTION}

The GIS model for Landfill Sitting, is designed to contain the following main spatial categories and subcategories:

Category A.: NATURE/ECOSYSTEM. Subcategories/Layers: A.1 Coastline areas, A.2 High Slope areas (>80\%), A.3 Gorges/Canyons A.4 Caves, A.5 Rivers, A.6 NATURA areas, A.7 Forest areas, A.8 Faults.

Category B.: HUMAN ACTIVITIES. Subcategories/Layers: B.1 Urban areas, B.2 SportsEducation, B.3 Services for Tourism, B.4 Industry, B.5 Mining, B.6 Transportation, B.7 Telecommunications, B.8 Energy, B.9 Military Installations, B.10 Cultivation B.11 Grazing. 
Category C.: WATER RESOURCES/HYDROLOGY. Subcategories/Layers: C.1 Water springs, C.2 Boreholes, C.3 Networks, C.4 Reservoirs, C.5 Surface water.

Category D.: ANTIQUITIES. Subcategories/Layers: D.1 Modern, D.2 Byzantine/Roman, D3. Archeological.

For each of the above layers, specific restrictions take the form of buffering at specified distances S surrounding (and, usually, including) the above areas. The initial "buffered" layers (zones), containing the areas which are to be excluded from Landfill Sitting, are then defined (see also [5] and [6]). Next, the overlays (unions) between successive buffered layers are performed, by each category individually and by all categories as a total, as follows:

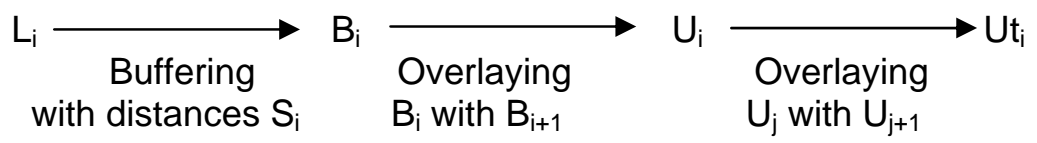

where:

$L_{i}$ are the Initial layers, $B_{i}$ are the buffered layers, $U i$ are the successive unions between the buffered layers of each category, and $\mathrm{Ut}_{\mathrm{i}}$ are the total unions between the successive unions of each subcategory. We have number of subcategories I = 8 (category $A)+11$ (category $B$ ) $+5($ category $C)+3($ category $D)=27$, thus $i=1, . ., 27$. Number of categories $j=4$, thus $j=1,4$

The above spatial analysis setup produces all the candidate landfill sites, as the remaining sites of the "exclusion process". For each remained candidate site, all the characteristics concerning its relationship to the exclusion criteria may be given: distances, visibilities, volumes etc. from layers Li.

\section{NUMERICAL SPATIAL CALCULATIONS PERFORMED}

The above GIS model was applied to the island of Crete. From the total region's area of $8,341.51 \mathrm{~km}^{2}$, all small islands surrounding Crete were excluded, leaving a total area of $8,264.62 \mathrm{~km}^{2}$ to be the initial Landfill Sitting research area.

In Table 1 we see the numerical results when applying all the criteria defined above. In column "CATEGORY" the main category is shown; in column "EXCLUSION CRITERION" the subcategory is defined; in column "DESCRIPTION" a short description of the subcategory follows; in column " $\mathrm{S}(\mathrm{Km})$ " the buffer distance in Km defined for each subcategory appears; in column " $E\left(\mathrm{~km}^{2}\right)$ " we define the area in $\mathrm{Km}^{2}$ excluded for Landfill Sitting, as defined solely by each subcategory; in column "Erem $\left(\mathrm{Km}^{2}\right)$ " we present the remaining area which is suitable for Landfill Sitting in $\mathrm{Km}^{2}$. This field is defined as $8,264.62 \mathrm{Km}^{2}-\mathrm{E}\left(\mathrm{km}^{2}\right)$; the next column "\%excl. area" is the \% percentage of the excluded area to the total area; in the following column "Erem_add $\left(\mathrm{Km}^{2}\right)$ " we give the remaining area (in $\mathrm{Km}^{2}$ ) in an additive manner, i.e., when subcategory $\mathrm{i}$ is overlayed with subcategory $\mathrm{i}+1$; the percentage of the additive remaining area is shown in the last column "\%excl.area(add)". The total areas to be excluded by each category, are shown in the last row of each category group, together with the remaining areas and their percentage to the total area. The total areas when applying all categories are shown in the last row of the table ("TOTAL UNIONS") as area excluded, area remained, and percentage of the excluded area to the total area.

As an example of reading this table, the exclusion criterion "A1 Coastline areas" was created by applying a buffer distance of $S=0.1 \mathrm{Km}$ surrounding all coasts. The area of this coastal zone is $101.90 \mathrm{Km}^{2}$, and the remaining area for site selection (due to this criterion only) is $8,162,72 \mathrm{~km}^{2}$.

The percentage of this excluded area is $1.23 \%$ of the total area (which is $8,264.62 \mathrm{Km}^{2}$ ). Next, the high slope areas (criterion A2) were produced by applying a buffer distance of $0.1 \mathrm{Km}$ to the high slope areas. The area of high slopes is $158.74 \mathrm{Km}^{2}$, the remaining area for site selection (due to this criterion only) is $8,105.88 \mathrm{Km}^{2}$, and the percentage of this excluded area is $1.92 \%$ of the total area. Now, combined with the A1 criterion (coastline areas) the total area due to the union of these two criteria is $258.52 \mathrm{Km}^{2}$ (less than the sum of the individual 
exclusion areas $101.90+158.74=260.64 \mathrm{Km}^{2}$, due to overlaps), and the remaining area from the combined A1 and A2 criteria is $8,005.80 \mathrm{Km}^{2}$, which corresponds to $3.13 \%$ of the total area, and so on.

Table 1. Numerical results of the GIS model for Landfill Sitting

\begin{tabular}{|c|c|c|c|c|c|c|c|c|c|}
\hline $\begin{array}{l}\text { CATE- } \\
\text { GORY }\end{array}$ & $\begin{array}{l}\text { EXCLUSION } \\
\text { CRITERION }\end{array}$ & DESCRIPTION & $\underset{(\mathrm{Km})}{\mathrm{S}}$ & $\underset{\left(\mathrm{km}^{2}\right)}{E}$ & $\begin{array}{l}\text { Erem } \\
\left(\mathbf{k m}^{2}\right)\end{array}$ & $\begin{array}{c}\% \text { excl. } \\
\text { area }\end{array}$ & $\begin{array}{l}\text { E_add } \\
\left(\mathrm{Km}^{2}\right)\end{array}$ & $\underset{\left(\mathrm{km}^{2}\right)}{\operatorname{Erem} \text { add }}$ & $\begin{array}{c}\text { \%excl. } \\
\text { area } \\
\text { (add) }\end{array}$ \\
\hline \multirow{8}{*}{ 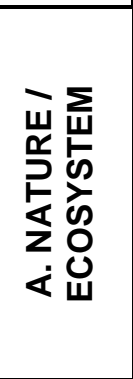 } & A1 & Coastline areas & 0.1 & 101.90 & $8,162.72$ & 1.23 & 101.90 & $8,162.72$ & 1.23 \\
\hline & $\mathrm{A} 2$ & High slope areas & 0.1 & 158.74 & $8,105.88$ & 1.92 & 258.82 & $8,005.80$ & 3.13 \\
\hline & A3 & Gorges & 0.3 & 199.35 & $8,065.27$ & 2.41 & 424.92 & $7,839.70$ & 5.14 \\
\hline & A4 & Caves & 0.3 & 11.30 & $8,253.32$ & 0.14 & 432.40 & $7,832.22$ & 5.23 \\
\hline & A5 & Rivers & 0.3 & 434.98 & $7,829.64$ & 5.26 & 851.61 & $7,413.01$ & 10.30 \\
\hline & $\mathrm{A} 6$ & NATURA areas & 0.1 & $2,431.84$ & $5,832.78$ & 29.42 & $2,997.32$ & $5,267.30$ & 36.27 \\
\hline & A7 & Forest areas & 0.1 & 338.00 & $7,926.62$ & 4.09 & $3,083.99$ & $5,180.63$ & 37.32 \\
\hline & A8 & Faults & 0.1 & $1,441.97$ & $6,822.65$ & 17.45 & $3,944.43$ & $4,320.20$ & 47.73 \\
\hline & \multicolumn{2}{|l|}{ UNIONS } & & $3,944.43$ & $4,320.20$ & 47.73 & & & \\
\hline \multirow{11}{*}{ 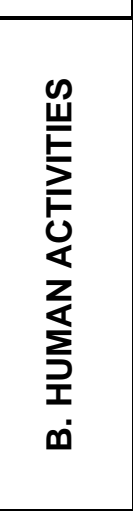 } & B1 & Urban areas & 0.5 & $1,887.81$ & $6,376.82$ & 22.84 & $1,887.81$ & $6,376.82$ & 22.84 \\
\hline & B2 & Sports-Education & 0.3 & 6.75 & $8,257.87$ & 0.08 & $1,891.66$ & $6,372.96$ & 22.89 \\
\hline & B3 & Services for Tourism & 0.5 & 810.57 & $7,454.05$ & 9.81 & $2,587.19$ & $5,677.43$ & 31.30 \\
\hline & B4 & Industry & 0.3 & 6.75 & $8,257.88$ & 0.08 & $2,591.26$ & $5,673.36$ & 31.35 \\
\hline & B5 & Mining & 0.1 & 7.21 & $8,257.41$ & 0.09 & $2,597.52$ & $5,667.10$ & 31.43 \\
\hline & B6 & Transportation* & $0.1,1,3$ & 60.51 & $8,204.11$ & 0.73 & $2,776.72$ & $5,487.91$ & 33.60 \\
\hline & B7 & Telecommunications & 0.2 & 9.37 & $8,255.25$ & 0.11 & $2,785.98$ & $5,478.64$ & 33.71 \\
\hline & B8 & Energy & 0.1 & 136.82 & $8,127.80$ & 1.66 & $2,894.36$ & $5,370.26$ & 35.02 \\
\hline & B9 & Military Installations & 1 & 74.54 & $8,190.08$ & 0.90 & $2,900.80$ & $5,363.82$ & 35.10 \\
\hline & B10 & Cultivation & 0.1 & 36.87 & $8,227.75$ & 0.45 & $2,928.12$ & $5,336.50$ & 35.43 \\
\hline & B11 & Grazing & 0.1 & $3,084.88$ & $5,179.74$ & 37.33 & $5,074.41$ & $3,190.21$ & 61.40 \\
\hline & \multicolumn{2}{|l|}{ UNIONS } & \multicolumn{2}{|c|}{\begin{tabular}{|l|l|}
$5,074.41$ \\
\end{tabular}} & $3,190.21$ & 61.40 & & & \\
\hline \multirow{6}{*}{ 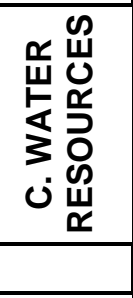 } & C1 & Water Springs & 0.5 & 40.32 & $8,224.30$ & 0.49 & 40.32 & $8,224.30$ & 0.49 \\
\hline & $\mathrm{C} 2$ & Boreholes & 0.5 & $1,142.59$ & $7,122.03$ & 13.83 & $1,170.35$ & $7,094.27$ & 14.16 \\
\hline & $\mathrm{C} 3$ & Networks & 0.5 & 41.38 & $8,223.24$ & 0.50 & $1,198.12$ & $7,066.50$ & 14.50 \\
\hline & $\mathrm{C} 4$ & Reservoirs & 0.3 & 12.34 & $8,252.28$ & 0.15 & $1,207.09$ & $7,057.53$ & 14.61 \\
\hline & $\mathrm{C} 5$ & Surface Water & 0.3 & 136.52 & $8,128.10$ & 1.65 & $1,325.07$ & $6,939.55$ & 16.03 \\
\hline & \multicolumn{2}{|l|}{ UNIONS } & \multicolumn{2}{|c|}{$1,325.07$} & $6,939.55$ & 16.03 & & & \\
\hline \multirow{5}{*}{ 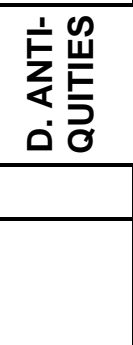 } & D1 & Modern & 0.5 & 7.85 & $8,256.77$ & 0.09 & 7.85 & $8,256.77$ & 0.09 \\
\hline & $\mathrm{D} 2$ & Byzantine/Roman & 0.5 & 24.70 & $8,239.92$ & 0.30 & 32.55 & $8,232.08$ & 0.39 \\
\hline & D3 & Archeological & 0.5 & 55.62 & $8,209.00$ & 0.67 & 85.58 & $8,179.04$ & 1.04 \\
\hline & \multicolumn{2}{|l|}{ UNIONS } & & 85.58 & $8,179.04$ & 1.04 & & & \\
\hline & \multicolumn{2}{|l|}{$\begin{array}{l}\text { TOTAL } \\
\text { UNIONS }\end{array}$} & & $6,830.52$ & $1,434.10$ & 82.65 & & & \\
\hline
\end{tabular}

* For "B.6 Transportation" exclusion criterion the buffer distances were $0.1 \mathrm{Km}$ for main roads, 1 $\mathrm{Km}$ for ports and $3 \mathrm{Km}$ for airports.

In Figure 1 we can see the remaining area changes due to the application of the restrictions imposed by all Categories A-D. The start of the diagram "None" corresponds to the initially available area $\left(8,264.62 \mathrm{Km}^{2}\right)$. 


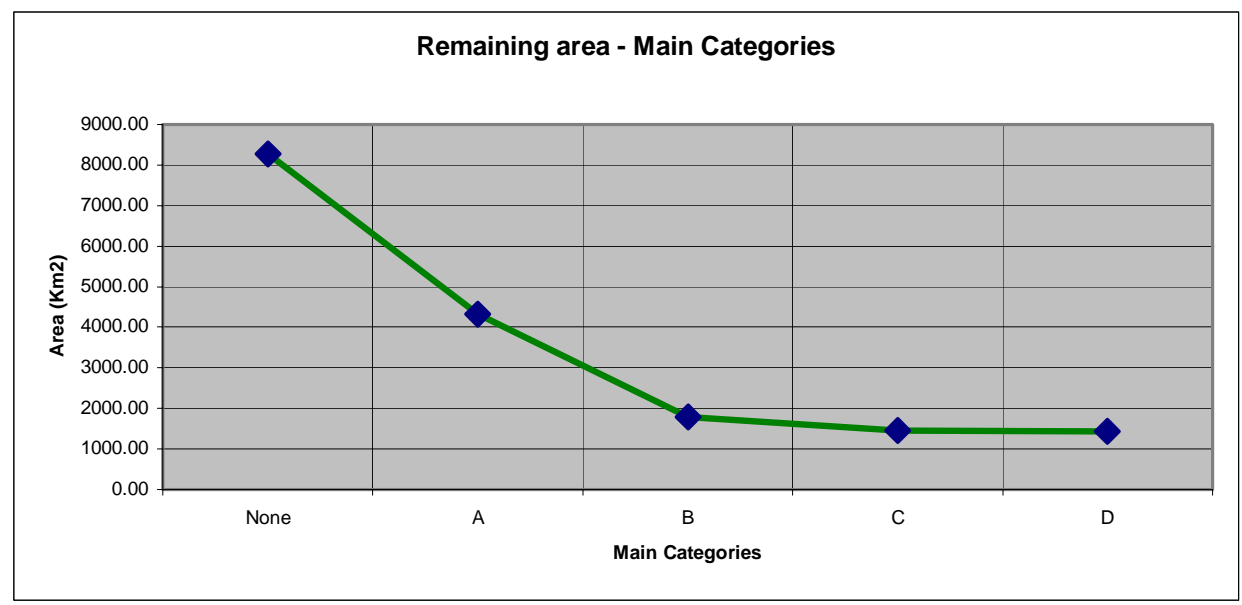

Figure 1. Remaining area changes due to all Categories A-D

\section{DISCUSSION OF THE RESULTS}

First of all, let us notice that the current set of distances selected, constitute a "moderate restrictions" type of scenario. The buffer distances may increase, for a "strict" scenario, or decrease, to produce a "loose" scenario (sensitivity analysis). The results of this "moderate" scenario gave a total excluded area of $6830.52 \mathrm{Km}^{2}$, which corresponds to $82.65 \%$ of the total area. Alternatively, using our model, a total area of $1,434.10 \mathrm{Km}^{2}(17.35 \%$ of the total area) remains to be examined for Landfill Sitting, and the model shows exactly where this "candidate" area is located. Therefore, as a next stage, site evaluation and ranking will take place only on that area, saving time and efforts for future investigators/policy makers/scientists. Examination and inspection of these sites and modification of our GIS model to function at a local scale is needed for a final decision. All remained sites though, are accompanied by our current GIS model results, which show why they were not rejected at this stage.

The GIS model results show that the highest percentage of the excluded areas is due to urban activities (61.40\%), and the lowest percentage (1.04\%) steams from the antiquities protection restrictions. A $47.73 \%$ of the total area is excluded based solely on natural criteria (Morphological conditions), whereas $16.03 \%$ of the total area is out from Landfill Sitting due to their intense water resources use (drinking and irrigating).

If we are to look at the individual subcategories, the largest area (37.33\%) was excluded for grazing areas protection, the second higher area (29.42\%) was excluded as being NATURA areas, and the third higher area (22.84\%) was excluded as being urban areas. Relatively large areas were excluded being close to existing boreholes (13.83\%). On the other hand, low impact on Landfill Sitting areas exclusion gave the areas surrounding natural caves $(0.14 \%)$, the sports-education regions $(0.08 \%)$, the Industrial regions $(0.08 \%)$, the mining areas $(0.09 \%)$, and the modern antiquities protection areas $(0.09 \%)$.

\section{CONCLUSIONS}

Using the proposed GIS model for Landfill Sitting research, we arrive at safe conclusions concerned the candidate sites, since we ensure that: (a) the excluded areas are precisely defined taking into account environmental, archeological and other law restrictions (b) the region's sustainability is preserved in both the environment and the economy, since no action takes place at existing or planned urban areas, important land uses, sensitive ecosystems etc. Furthermore, the actual "Landfill carrying capacity" of the region is defined, i.e., the total potential area which can be used for Landfill Sitting.

The evaluation of the remaining sites depends initially on their "GIS characteristics" derived from above GIS model setup (position-distance-orientation-functionality) and, at the final evaluation stage, on the Landfill Sitting functionality itself (life years, traffic, capacity etc). 
Future developments of the proposed model may include: Sensitivity analysis to detect the effect of buffer distances changes on the total remaining area, inclusion of dynamic spatial layers (see [2] and [3]) to account for spatial layers changes, future plans for public works, urban expansion candidate areas, and general land use changes (natural disasters, fires, floods, rural areas shrinkage, changes in grazing areas, city plans modifications). Finally, the link to existing (non-spatial) Landfill models [4] is now under development by the authors.

\section{REFERENCES}

1. Burrough P.A. (1983) Principles of Geographical Information Systems for Land Resources Assessment, Monographs on Soil and Resources Survey 12, Clarendon Press, .

2. Despotakis V.K. (1991) Sustainable Development Planning Using Geogaphic Information Systems, Ph. D. Dissertation, Centrale Huisdrukkerij Vrije Universiteit, Free University Amsterdam.

3. Despotakis V.K., Nijkamp P. and Giaoutzi M., (1993), Dynamic G.I.S. Models for Regional Sustainable Development, in Geographic Information Systems, Spatial Modeling, and Policy Evaluation, Springer-Verlag.

4. Economopoulos A.P. (2005) A Multicriteria Model for Landfill Sitting, Technical Chambre of Greece, Athens.

5. Halvadakis C.P. (1993) Municipal solid waste landfill sitting in Greece - The case of the greater Hania region, Crete, Ecistics, 359, 45-52.

6. Vassiloglou V., (2001), Multicriteria Analysis and Evaluation of New Landfill Areas, Report, Hydraulic and Environmental Engineering Division, Dept. of Civil Engineering, Aristotle University of Thessaloniki. 